\title{
Halving global GHG emissions by 2050 without depending on nuclear and CCS
}

\author{
Osamu Akashi • Tatsuya Hanaoka • Toshihiko Masui • Mikiko Kainuma
}

Received: 26 November 2012 / Accepted: 17 September 2013 / Published online: 2 October 2013

(C) The Author(s) 2013. This article is published with open access at Springerlink.com

\begin{abstract}
In this paper, we assessed the technological feasibility and economic viability of the mid-term (until 2050) GHG emission reduction target required for stabilization of radiative forcing at $2.6 \mathrm{~W} / \mathrm{m} 2$. Given the apparent uncertainty surrounding the future deployment of nuclear and CCS technologies, we intensively investigated emission reduction scenarios without nuclear and CCS. The analysis using AIM/Enduse[Global] shows the emission reduction target is technologically feasible, but the cost for achieving the target becomes very high if nuclear and CCS options are limited. The main reason for the cost rise is that additional investment for expensive technologies is required in order to compensate for emission increases in the steel, cement and power generation sectors in the absence of CCS. On the other hand, if material efficiency improvement measures, such as material substitution, efficient use of materials and recycling, are taken, the cost of achieving the emission reduction target is significantly reduced. The result indicates the potentially important role of material efficiency improvement in curbing the cost of significant GHG emission reductions without depending on nuclear and CCS.
\end{abstract}

\section{Introduction}

Under the Copenhagen accord in COP 15 , international society agreed the long-term climate goal of holding the increase in the global average temperature below $2{ }^{\circ} \mathrm{C}$. The stabilization of temperature at this low level requires a significant reduction of GHG emissions in the first half of 21 st century as well as in the latter half of the century (Rogelj et al. 2011). IPCC (2007), for example, show that limiting the increase in the global mean temperature to less than $2.4^{\circ}$ above the pre-industrial level, using a best estimate of climate sensitivity, requires

This article is part of the Special Issue on "The EMF27 Study on Global Technology and Climate Policy Strategies" edited by John Weyant, Elmar Kriegler, Geoffrey Blanford, Volker Krey, Jae Edmonds, Keywan Riahi, Richard Richels, and Massimo Tavoni.

Electronic supplementary material The online version of this article (doi:10.1007/s10584-013-0942-x) contains supplementary material, which is available to authorized users.

O. Akashi $(\bowtie)$

Musashino University, 3-3-3 Ariake, Koto-ku, Tokyo 135-8181, Japan

e-mail: o_akashi@musashino-u.ac.jp

T. Hanaoka $\cdot$ T. Masui $\cdot$ M. Kainuma

National Institute for Environmental Studies, 16-2 Onogawa, Tsukuba, Ibaraki 305-8506, Japan 
reductions in $\mathrm{CO} 2$ emissions of $50 \%-85 \%$ in 2050 relative to the 2000 level. On the other hand, there is uncertainty regarding future deployment of large-scale low-carbon technologies. Since the Fukushima accident in March 2011 there has been increasing skepticism among citizens about the safety of nuclear energy, and some countries (e.g. Germany, Switzerland) have decided to phase-out their existing nuclear power plants. Carbon capture and storage (CCS) is another large-scale technology associated with uncertainty of various environmental impacts (IPCC 2005). Although there are high expectations for the role of CCS in reducing CO2 emissions (see for example Akashi and Hanaoka 2012), there are still uncertainties surrounding its technological reliability and social acceptability. Given the uncertainty regarding the future deployment of nuclear and CCS, it is important to assess the impacts of the unavailability of these technologies on climate policy.

A number of studies have explored an implication of lack of technologies in climate policy scenario. Okagawa et al. (2012), for example, have investigated economic impact of absence of nuclear and CCS on climate policy by using computable general equilibrium model. Krey and Riahi (2009) have assessed implication of technology failure for feasibility, costs and likelihood of achieving climate target by using energy system model. However, a detailed technological assessment on implication of lack of technologies in climate policy scenario has yet been conducted.

This paper highlights the findings of scenario analyses conducted using the AIM/Enduse[Global] model as part of EMF 27 (see Kriegler et al. in this special issue). The main goal is to investigate the technological feasibility and economic viability of a climate policy that does not depend on nuclear and CCS in a mid-term perspective (until 2050). In particular, it focuses on the radiative forcing target of $2.6 \mathrm{~W} / \mathrm{m} 2$, which roughly corresponds to the climate goal of limiting increase in the global average temperature below $2{ }^{\circ} \mathrm{C}$ above pre-industrial level.

\section{Scenarios and model description}

\subsection{Scenarios}

We use a scenario analysis as a framework for investigating the feasibility of climate policy. Four scenarios are explored for the analysis, as described in Table 1.

Table 1 Scenarios developed in this paper

\begin{tabular}{ll}
\hline Scenario name & Description \\
\hline Baseline & $\begin{array}{l}\text { No climate policy is implemented. There is no incentive to reduce GHG emissions. } \\
\text { Corresponding to Base FullTech scenario (Kriegler et al. in this special issue) }\end{array}$ \\
& $\begin{array}{l}\text { Reducing global GHG emissions by } 50 \% \text { relative to the } 1990 \text { level aiming at } \\
\text { limiting radiative forcing to } 2.6 \mathrm{~W} / \mathrm{m} 2 \text { in } 2100 . \text { (See Section } 4 \text { for more detail.) } \\
\text { Corresponding to } 450 \text { FullTech scenario (Kriegler et al. in this special issue) }\end{array}$ \\
& $\begin{array}{l}\text { Variant of } 50 \% \text { default scenario. } \\
\text { CCS is not available and no new nuclear power plants are built. (See Section } 5 \\
\text { for more detail.) }\end{array}$ \\
& $\begin{array}{l}\text { Variant of } 50 \% \text { default scenario. } \\
\text { CCS is not available and no new nuclear power plants are built. Material efficiency } \\
\text { is improved (e.g. reduction of material demand, recycling and material } \\
\text { substitution). (See Section } 5 \text { for more detail.) }\end{array}$ \\
\hline
\end{tabular}




\subsection{Modeling framework}

In order to assess climate policy scenarios, the following models of the AIM, Asia-Pacific Integrated Model (Kainuma et al. 2003) are used:

- AIM/Enduse[Global]: a multi-regional, recursive dynamic, techno-economic model with a detailed representation of technologies

- AIM/Impact[Policy]: a global dynamic optimization model coupled with a simple climate model.

The AIM/Enduse[Global] is a dynamic recursive, techno-economic model for mid- to long-term climate change mitigation policy assessment. The version of AIM/Enduse[Global] used in this paper covers energy sectors (through the phase of energy production to end-use) and non-energy sectors (e.g. agriculture, waste, and F-gases sectors) (Akashi et al. 2012). It simulates energy consumption and GHG emissions (e.g., CO2, CH4, N2O, HFC, PFC and SF6) with a detailed framework for technology selection. The detailed description of technologies is a major feature of the model (See Electronic Supplemental Material for a full list of technologies used in the model). The technology selection is formulated by linear programming algorithms that minimize the total system cost (including the initial investment, operation, and maintenance costs of technologies, energy cost, and other costs such as carbon tax) given fixed service demands (e.g. steel production, passenger transport, space heating demand). A detailed formulation of the model can be found in Kainuma et al. (2003). In this model, choice of technologies is endogenously projected depending on energy and carbon prices and characteristics of energy systems. ${ }^{1}$ Thus, in all scenarios in this study, changes in energy consumptions and GHG emissions are endogenously projected as a result of technology choices. For example, energy savings in climate policy scenarios are endogenously projected in response to increasing carbon and energy prices.

AIM/Impact [Policy] is used in combination with AIM/Enduse[Global] in order to assess climate policy scenarios. First, AIM/Impact [Policy] is used in order to estimate the GHG emission pathway for limiting radiative forcing to $2.6 \mathrm{~W} / \mathrm{m} 2$ (See Hijioka et al. 2008 for more detail of AIM/Impact [Policy]). Then, AIM/Enduse [Global] is used for detailed technological assessment of the emission pathway.

\subsection{Scenario assumptions}

\subsubsection{Socio-economic parameters}

A necessary step of scenario development is to set socio-economic parameters. The major assumptions used in this paper are summarized in Table 2. For the population scenario we apply a UN medium variant (UN 2009) in which the world population reaches 9.2 billion by 2050. For the GDP scenario we assume that the world GDP grows by $2.7 \%$ per year from 2005 to 2050 on average, a rate similar to that in the SRES B2 scenario (IPCC 2000). Based on the assumed population and GDP, we project future service demands such as industrial production and transportation volume, etc. Akashi et al. (2011) and Hanaoka et al. (2009) offer detailed descriptions of service demand projections. Global crude steel production

\footnotetext{
${ }^{1}$ In this model, technological parameters such as cost and efficiency are exogenously assumed. This means endogenous technological changes are not taken into account. The exogenous assumptions (e.g. cost and efficiency) are same in all regions and all scenarios in this study. However, deployment of technology is different depending on regions and scenarios as a result of technology choices.
} 
Table 2 Summary of socio-economic parameters used in this paper

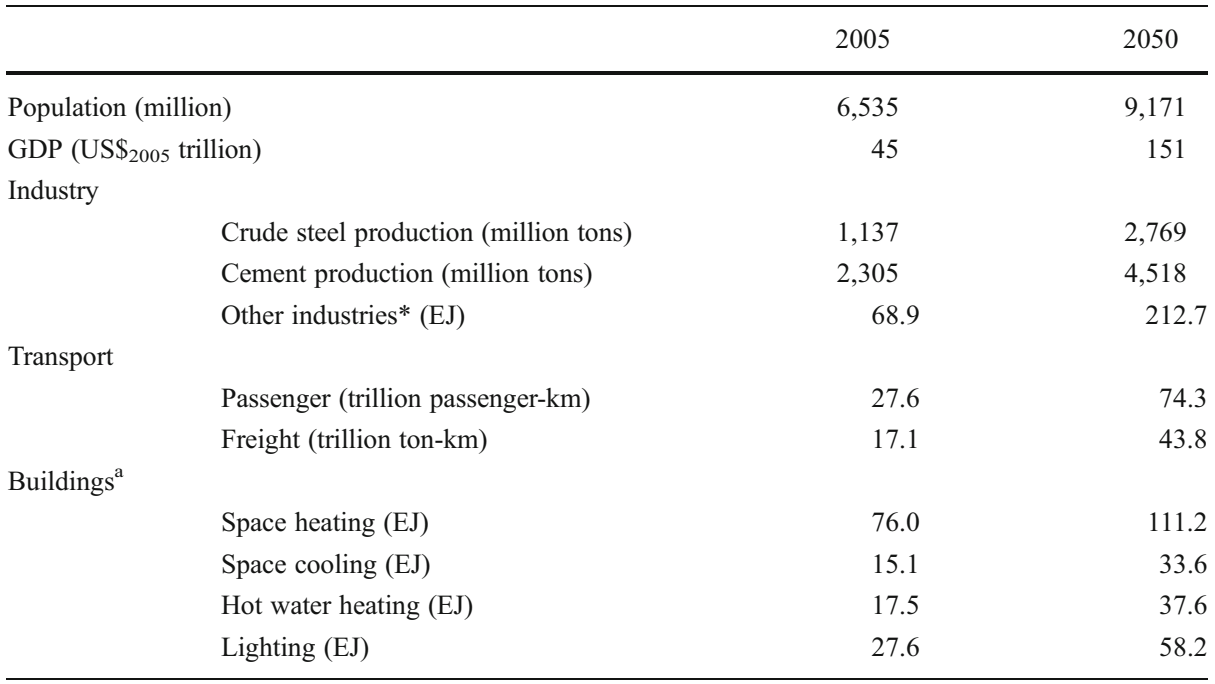

\footnotetext{
${ }^{\text {a }}$ Energy service demand is expressed in the energy unit. It denotes demand for effective energy (not actual energy consumption). Actual energy consumption to meet the effective energy demand is calculated by the model considering energy efficiency of end-use technologies
}

increases by $2.0 \%$ /year between 2005 and 2050, or by 2.4 times throughout the whole period. Passenger and freight transport volume grow by about $2 \%$ year worldwide on average between 2005 and 2050 .

\subsubsection{Nuclear and CCS}

The deployment of nuclear power plants is subject to political decisions, which depend not only on economic aspects but also social dimensions. For this reason we do not consider the deployment of nuclear power plants as a decision variable in the cost-minimization model, but rather as an externally determined parameter. Thus, we externally develop a future nuclear power capacity scenario. The scenario is based on governmental plans (World Nuclear Association, http:/www.world-nuclear.org/info/reactors.html). In this scenario, total global nuclear power plant capacity increases from $364 \mathrm{GW}$ in 2005 to $557 \mathrm{GW}$ in 2050.

We assume worldwide $\mathrm{CO} 2$ storage capacity is about $4600 \mathrm{GtCO} 2$. This value is a median of the estimated values from various studies (Dooley et al. 2006; Hendriks et al. 2004; IEA 2008, 2010). The maximum annual storage rate is set based on an ambitious growth pathway in Energy Technology Perspectives 2001 (IEA 2010). In this scenario, maximum annual $\mathrm{CO} 2$ storage in 2050 in the world is about $10 \mathrm{GtCO} 2$.

\section{Baseline scenario}

In the baseline scenario, global GHG emissions are estimated to reach $68 \mathrm{GtCO} 2$-eq in 2050, 1.5 times those in 2005 (Fig. 1). The CO2 emissions from fossil fuels and industrial processes increase faster than GHG emissions, and become 1.8 times those in 2005. The primary energy consumption grows at a similar rate as $\mathrm{CO} 2$ emissions during the same 


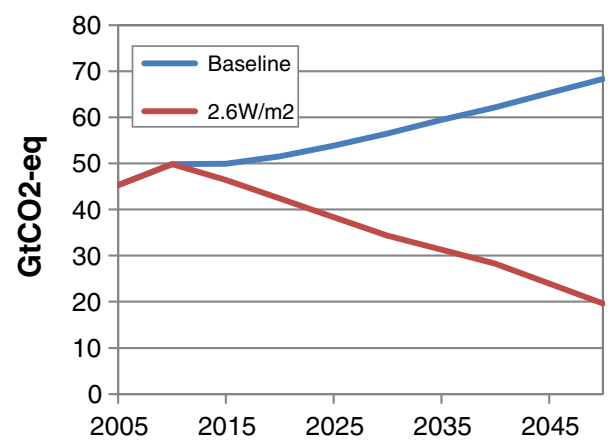

Fig. 1 Global GHG emission paths

period (Fig. 2). This means increase of $\mathrm{CO} 2$ emissions is mainly attributed to the growing amount of energy consumption and not to carbon intensity of energy. The final energy consumption increases at about the same rate as primary energy consumption. The share of electricity in final energy consumption increases over time as electrification (shift from fossil fuel or traditional biomass to electricity) progresses in end-use sectors, mainly in developing countries. This trend makes electricity consumption increase at a rapid rate, reaching 2.5 times the 2005 level. Regarding power generation, fossil fuels remain the dominant energy sources with their share increasing from $66 \%$ in 2005 to $77 \%$ in 2050 . Nuclear power has a decreasing share as capacity expansion is slower compared to gas and coal power plants. The role of renewable energies such as solar, wind and biomass is relatively small because there is little incentive to invest in such energies in the absence of a climate policy.

Table 3 shows regional GHG emissions for the major economies. In developing regions, GHG emissions are projected to increase at high rate of growth due to rapid economic growth: GHG emissions in China and India reach 2- and 3-fold the 2005 levels by 2050, respectively.

a

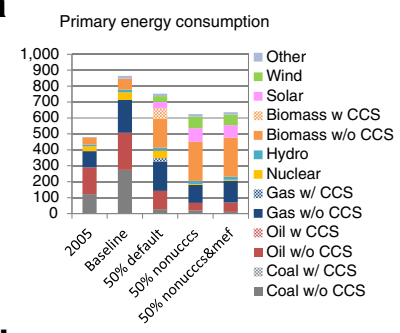

d

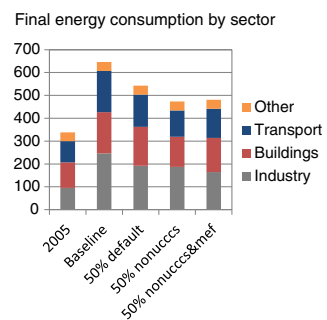

b

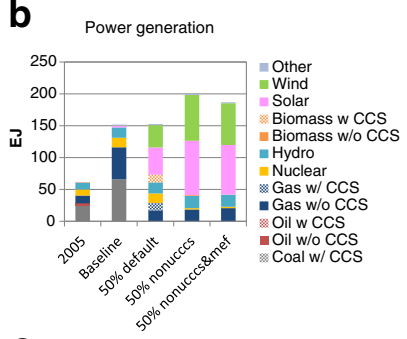

Q $\mathrm{CO} 2$ emissions from fossil fuels and industrial process

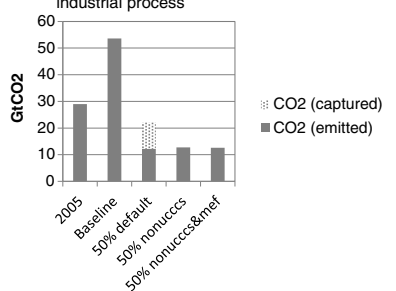

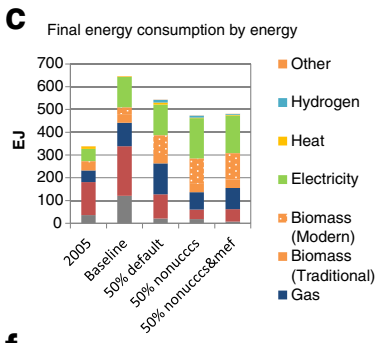

f

Cumulative additional cos from 2005 to $2050^{*}$

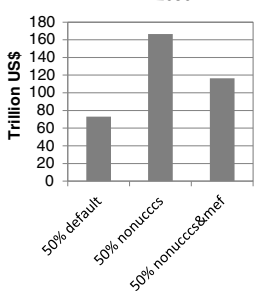

Fig. 2 Summary of scenarios in this paper. Energy consumption and CO2 emissions in 2005 and 2050 and cumulative cost from 2005 to 2050 
Table 3 Regional GHG emissions in major economies in all scenarios

\begin{tabular}{cllllll}
\hline & USA & EU & Japan & Russia & China & India \\
\hline 2005 & 6,955 & 5,073 & 1,405 & 2,345 & 7,751 & 2,112 \\
2050 & & & & & \\
Baseline & 7,972 & 6,582 & 1,319 & 3,707 & 15,653 & 6,642 \\
$\quad(2005=1)$ & $(1.15)$ & $(1.30)$ & $(0.94)$ & $(1.58)$ & $(2.02)$ & $(3.15)$ \\
$50 \%$ default & 1,132 & 2,982 & 860 & 908 & 2,754 & 2,715 \\
$\quad($ Baseline=1) & $(0.14)$ & $(0.45)$ & $(0.65)$ & $(0.24)$ & $(0.18)$ & $(0.41)$ \\
$50 \%$ nonucccs & 1,199 & 2,365 & 684 & 699 & 3,097 & 2,370 \\
$\quad($ Baseline=1) & $(0.15)$ & $(0.36)$ & $(0.52)$ & $(0.19)$ & $(0.20)$ & $(0.36)$ \\
$50 \%$ nonucccs\&mef & 1,426 & 2,509 & 712 & 685 & 2,866 & 2,032 \\
$\quad($ Baseline=1) & $(0.18)$ & $(0.38)$ & $(0.54)$ & $(0.18)$ & $(0.18)$ & $(0.31)$ \\
\hline
\end{tabular}

On the other hand, developed regions have moderate rate of growth. In Japan, GHG emissions gradually decrease over time due to decreasing population and low economic growth.

\section{$42.6 \mathrm{~W} / \mathrm{m} 2$ scenario: $50 \%$ reduction by 2050}

The global GHG emission trajectory for limiting radiative forcing to $2.6 \mathrm{~W} / \mathrm{m} 2$ in 2100 is estimated using the AIM/Impact[Policy]. In this trajectory, the global GHG emissions in 2050 are reduced to about $20 \mathrm{GtCO} 2$-eq, $50 \%$ reduction relative to the 1990 level (Fig. 1). The AIM/Enduse[Global] is used to conduct a technologically detailed assessment of $50 \%$ reduction by 2050 . This scenario is called the "50\% default scenario". In this scenario, a global uniform equal carbon price is applied on all regions and sectors for achieving the global GHG emission target.

Figure 2 shows $\mathrm{CO} 2$ emissions and energy consumption in the $50 \%$ default scenario simulated by AIM/Enduse[Global]. In the $50 \%$ default scenario, global CO2 emissions from fossil fuels and industrial processes are reduced by $77 \%$ relative to the baseline scenario (Fig. 2e). The reduction is achieved by mainly three types of measures:

- energy saving,

- carbon intensity improvement,

- CCS.

The first measure, energy saving, plays a moderate role in reducing $\mathrm{CO} 2$ emissions in the $50 \%$ default scenario; primary energy consumption is reduced by $13 \%{ }^{2}$ from baseline scenario (Fig. 2a).

On the other hand, the second measure, carbon intensity, is greatly improved by fuel switching in the $50 \%$ default scenario. In this scenario the share of fossil fuels in primary energy consumption is reduced to $46 \%$ in 2050 . In other words, more than a half of the primary energy is provided by zero (or net negative) emission sources. These include bioenergy technologies in combination with CCS, which results in net negative emissions when used in a sustainable way. The renewable energies, such as hydro, biomass, solar and wind, account for $70 \%$ of power generation, collectively (Fig. 2b). Together with nuclear energy, zero (or net

\footnotetext{
$\overline{2}$ These energy savings are on account of endogenous response to increasing carbon and energy prices.
} 
negative) emission energies account for $80 \%$ of power generation. The rest (20\%) is supplied by gas power plants, half of which are equipped with CCS.

$\mathrm{CCS}$, the third type of $\mathrm{CO} 2$ emission reduction, plays a big role. The amount of $\mathrm{CO} 2$ captured in the $50 \%$ default scenario is about $10 \mathrm{GtCO} 2$ in 2050 (Fig. 2e). This means that $45 \%$ of the total amount of $\mathrm{CO} 2$ generated from fossil fuel combustion and industrial processes is captured using CCS technology. CCS is used in steel (1.0 GtCO2), cement (1.5 $\mathrm{GtCO} 2)$, power generation $(5.1 \mathrm{GtCO} 2)$ and other transformation sectors $(2.2 \mathrm{GtCO} 2)$ in 2050 .

The cumulative additional cost (i.e. the sum of investment, operation, and maintenance costs of technologies and energy cost addition to baseline scenario. Carbon prices are not included.) From 2005 to 2050 is estimated to be 73 trillion US\$. The regional GHG emissions in the $50 \%$ default scenario are shown in Table 3 . The regional emissions denote domestic emissions in each region under the globally uniform carbon price, and do not include carbon credit, which is traded internationally. The GHG emissions in 2050 in the $50 \%$ default scenario range from $14 \%$ to $65 \%$ of the baseline emissions. The variance of the reduction rate among regions stems from regional potential of emission reduction, which is influenced by baseline emission, energy price, availability of resources, industrial structure, characteristics of energy systems, etc. Japan, for example, has a low rate of emission reduction because of relatively small amount of renewable energy resources and CCS capacity. Note that emission reduction projected in this study represents emission reduction potentials under the globally uniform carbon price, and does not directly link to regional emission target.

\section{$550 \%$ reduction without nuclear and CCS}

\subsection{No nuclear and CCS scenario}

The analysis of the $50 \%$ default scenario shows that a $50 \%$ reduction of global GHG emissions by 2050 is technologically feasible. However, a question still remains regarding the acceptability of the scenario. Opposition to nuclear power has become stronger, particularly after the nuclear accident in Japan in March 2011. A recent study by the European Commission reveals that nuclear power is the least popular energy source, with more than half of respondents opposed to nuclear installations in the EU (EC 2011). A Japanese study on public opinions shows that at least more than a half of the country's citizens hope for a society that is not dependent on nuclear power (Energy and Environment council 2012). Public acceptance (or lack thereof) could also be a barrier to the widespread diffusion of CCS. There are different perceptions and opinions within the scientific, political, and civil society on CCS technology. For example, a study by the European Commission (EC 2011) indicated that more than $60 \%$ of people were anxious about the safety of $\mathrm{CO} 2$ storage in the EU, although the response varied by country from the lowest in Finland (50\%) to the highest in Greece $(84 \%)$.

Given the apparent uncertainty regarding future deployment of nuclear and CCS technologies, a scenario without dependence on these options ("50\% nonucccs scenario") was developed. In the $50 \%$ nonucces scenario, we assume a phase out of nuclear energy after 2010. This 'phase out' is defined as no construction of new nuclear power plants beyond those already under construction (excluding planned and proposed plants). In addition, lifetime extensions are not allowed in this scenario. This policy translates into $63 \mathrm{GW}$ of power generation capacity in 2050 , which is only $17 \%$ of that in 2005 . In addition, 
deployment of CCS is not allowed in all energy sectors, in all regions, and for all combinations with fossil fuel, bioenergy and industrial uses in this scenario.

Under the above-described conditions for nuclear and CCS, the technological feasibility of reducing global GHG by $50 \%$ in 2050 is assessed. The model analysis reveals that the $50 \%$ nonucces scenario is technologically feasible. However, further energy-saving and carbon intensity improvement are required in this scenario. Final energy consumption is reduced by $15 \%$ relative to the $50 \%$ default scenario (Fig. 2c). The carbon intensity improvement is achieved by combination of electrification and renewable energy deployment. The share of electricity in final energy consumption increases to $38 \%$, and $90 \%$ of electricity is produced by renewable energies in the $50 \%$ nonucces scenario (Fig. $2 \mathrm{~b}$ and c). These energy-savings and carbon intensity improvement require additional investment in technologies, which leads to an increase in the total cost for achieving the emission reduction target. In the $50 \%$ nonucces scenario, the total cumulative cost increases by 94 trillion US\$ relative to the $50 \%$ default scenario, resulting in a total sum of 166 trillion US\$ (Fig. 2f).

What is the main factor behind this significant increase in the cost? Sector-wise comparison of $\mathrm{CO} 2$ emissions between the $50 \%$ default and $50 \%$ nonucces scenarios shows an increase in emissions in the power generation, steel, and cement sectors in the $50 \%$ nonucccs scenario (Fig. 3). In these sectors CCS is such an important technological option in reducing $\mathrm{CO} 2$ that the other options are not able to take over the role of CCS for following reasons. The process of making steel from iron ore uses coal (in the form of coke) or gas as reduction agents and it is difficult to reduce $\mathrm{CO} 2$ emissions from that process without using CCS. Similarly, the process-induced CO2 from the clinker making process in the cement sector is difficult to reduce without using CCS. In the power generation sector, only CCS combined with bioenergy is the option that can provide net negative $\mathrm{CO} 2$. Thus, CCS has an indispensable role in deep cut of $\mathrm{CO} 2$ emissions in the steel, cement and power generation sectors, and an absence of CCS would have a large impact on these sectors. On the other hand, limitation of nuclear power has a relatively small impact, because there are other zeroemission options (e.g. renewable energies) available in the power generation sector; indeed, decrement of nuclear energy is covered by increment of renewable energies in the $50 \%$ nonucces scenario (Fig. 2b).

The increased emissions in the steel, cement and power sectors translate into a growing need for emission reductions in the other sectors, especially in the building and transport sectors (Fig. 3). The additional emission reductions in these sectors are achieved by mainly two types of measures, that is, energy savings and electrification. The $\mathrm{CO} 2$ emissions in the building sector are reduced by further introduction of high-efficiency building insulation and electrification of space heating. ${ }^{3}$ Over $85 \%$ of the space heating service is supplied by highefficiency heat pump air conditioners in combination with efficient insulations systems in the $50 \%$ nonucces scenario. The passenger transport sector achieves significant $\mathrm{CO} 2$ emissions reductions by widespread use of electric vehicles; it accounts for $65 \%$ of the passenger transport service (Fig. 4). Thus, electrification and energy efficiency improvement in the building and transport sectors are crucially important for feasibility of the $50 \%$ nonucccs scenario. The above-mentioned energy-saving and electrification technologies in the building and transport sectors are relatively expensive. The increased expense to those technologies is one of the main factors that make the total cost of the $50 \%$ nonucccs scenario very high (Fig. 5).

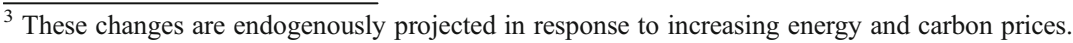




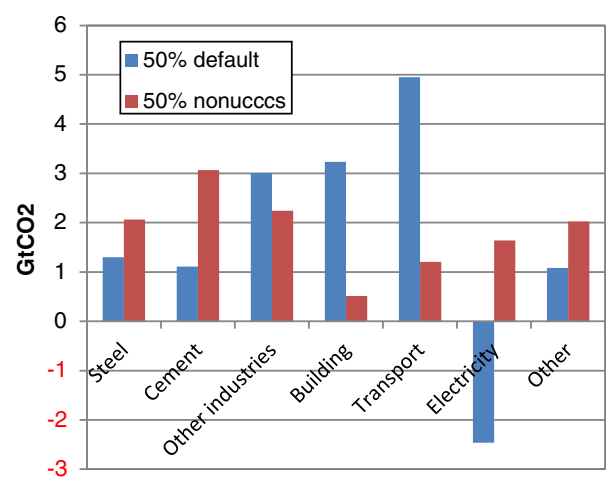

Fig. 3 Sectoral breakdown of $\mathrm{CO} 2$ emissions in $50 \%$ default and $50 \%$ nonucces scenarios

\subsection{Material efficiency improvement ${ }^{4}$ scenario}

The analysis in the previous section reveals that the technological potential for $\mathrm{CO} 2$ reduction in the steel and cement sectors is limited in the absence of CCS, and it makes the total cost of emission reduction high. However, there are non-technological $\mathrm{CO} 2$ emission reduction measures in these sectors.

IPCC (2007), for instance, shows that improvement of material efficiency can reduce $\mathrm{CO} 2$ emissions in the steel and cement sectors. Recycling of steel can reduce $\mathrm{CO} 2$ emissions significantly because the steel making process that uses scrap steel in electric furnaces consumes only $30 \%-40 \%$ of the energy consumed when steel is made from iron ore in blast furnaces (De Beer et al. 1998). The more fundamental countermeasure is reducing the amount of steel production itself. Higashi et al. (2012) shows that global demand for steel could be reduced by $40 \%$ as compared to the non-countermeasure case in 2050 by accelerated use of high-strength steel and improvements in material usage efficiency. The demand for cement also can be reduced. The global demand for cement is $25 \%$ lower in the low demand-case than in the high demand-case in IEA (2009). Another countermeasure in the cement sector is material substitution, for example the addition of wastes (e.g. blast furnace slag, fly ash) and geo-polymers to clinker IPCC (2007). Reducing clinker would potentially be an important emission reduction countermeasure because the process-induced $\mathrm{CO} 2$ from clinker production is the main source of emissions in the cement sector, accounting for more than a half of the total sectoral emissions (Worrell et al. 2001).

Given the potential importance of material efficiency in reducing $\mathrm{CO} 2$ emissions, a scenario with material efficiency improvement is developed. In this scenario, the following assumptions are made. ${ }^{5}$

- Assuming an accelerated use of high-strength steel and improvement in material usage efficiency, steel production is reduced by $40 \%$ relative to the baseline scenario in 2050 .

- Assuming an increased recycle rate, the share of electric furnaces in steel production increases from $33 \%$ (2005) to $70 \%$ (2050). The scrap steel used in this

\footnotetext{
${ }^{4}$ Material efficiency improvement refers to reduction of $\mathrm{CO} 2$ by material substitution, efficient use of materials and recycling.

${ }^{5}$ These assumptions are equally applied globally. The regional variations on income level, industrial structure and social aspects are not taken into account in this analysis.
} 

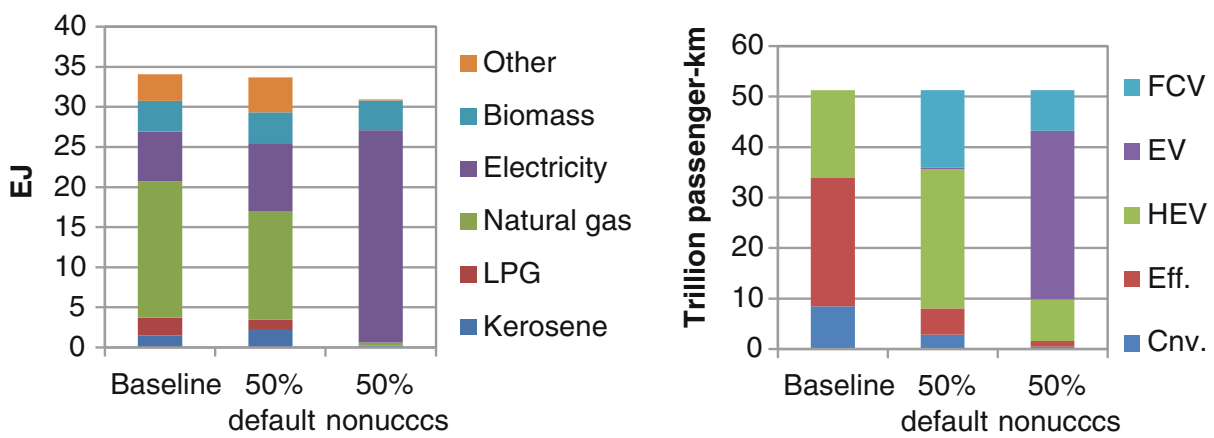

Fig. 4 Space heating technologies and passenger vehicles

scenario is 1.2 Gton in 2050. If the generation of steel scrap is assumed to be the same level as estimated in Higashi et al. (2012), the recycle rate in 2050 becomes $90 \%$.

- Cement production is assumed to be reduced by $25 \%$ relative to the baseline scenario in 2050. The intensity of cement production (cement production per unit of GDP) is the same level as the low demand-case in IEA (2009).

- The portion of clinker in cement is assumed to be $60 \%$ in 2050 as a world average, which is the same ratio as existing and well-used cement, such as Portland slag cement and Portland pozzolana cement (Worrell et al. 2001).

Under these material efficiency improvement assumptions, global CO2 emissions in 2050 in baseline scenario are projected to be reduced by $6 \%$ compared with default baseline scenario. It is noteworthy that impact of material efficiency improvement on $\mathrm{CO} 2$ emissions in the steel and cement sectors are large. The CO2 emissions in the steel and cement sectors in 2050 are reduced by $56 \%$ and $45 \%$, respectively, compared with default baseline scenario. As discussed in the previous section, $\mathrm{CO} 2$ emissions in these two sectors are difficult to be reduced in the absence of CCS. Thus, material efficiency improvement and its contribution to $\mathrm{CO} 2$ emission reduction in steel and cement sector might decrease the difficulty of achieving emission reduction target in the absence of CCS.

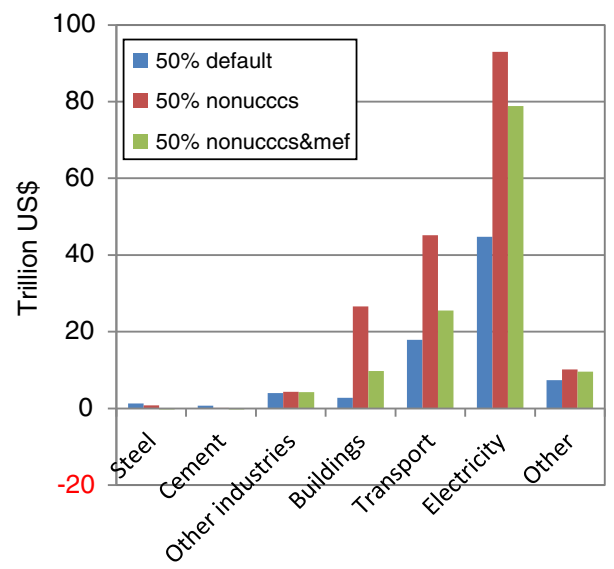

Fig. 5 Additional cumulative investment from 2005 to 2050 (undiscounted) 
Then, we explored economic impact of material efficiency improvement on $50 \%$ reduction of global GHG emissions without nuclear and CCS. This scenario is named $50 \%$ nonucccs\&mef scenario, in which above-described material efficiency improvement is assumed in addition to the assumptions in the $50 \%$ nonucces scenario. The model simulation reveals that the total cost of the nonucccs\&mef scenario is curbed by 52 trillion US\$ compared to the $50 \%$ nonucces scenario (Fig. 2f). In other words, the material efficiency improvement has an economic value of 52 trillion US\$ under the target of halving global GHG without depending on nuclear and CCS. It should be noted that the technological and social costs for improve material efficiency are not included in this analysis. The implication of the analysis is that if the costs for material efficiency improvement are somehow assumed at less than 52 trillion US\$, the material efficiency improvement policies are worth implementing. Figure 5 shows the sectoral breakdown of additional investment required in the $50 \%$ reduction scenarios. In the $50 \%$ nonucccs\&mef scenario, investment in the building, transport and power sectors are curbed significantly compared to the $50 \%$ nonucces scenario. This indicates that material efficiency improvement in the steel and cement sectors can soften the demand for drastic emission reductions in the other sectors and can reduce investment in expensive technologies in those sectors. Material efficiency improvement potentially has an important role in curbing the costs of significant GHG emission reduction without depending on nuclear and CCS.

\section{Conclusions}

In this paper, we assessed the technological feasibility and economic viability of halving global GHG emissions by 2050 without depending on nuclear and CCS. The analysis using AIM/Enduse [Global] shows the emission reduction target is technologically feasible even in the absence of nuclear and CCS. However, this scenario requires significant $\mathrm{CO} 2$ emission reductions in the building and transportation sector in order to compensate for emission increases in the steel, cement and power generation sectors. The analysis shows further energy-savings and drastic electrification in the building and transportation sectors are crucially important for the feasibility of this scenario. In order to make this scenario plausible, there will need to be a major transformation of the electric and road infrastructure. Regarding economic viability, the absence of nuclear and CCS options doubles the cost for achieving the target because of additional investment in expensive technologies in the building and transport sectors.

On the other hand, if material efficiency improvement measures (e.g. recycling and material substitution in the steel and cement sectors) are taken, the cost of achieving the emission reduction target is reduced significantly. This result indicates the potentially important role of material efficiency improvement in curbing the cost of significant GHG emission reductions without depending on nuclear and CCS.

Acknowledgments This research was supported by the Environment Research and Technology Development Fund (A-1103) of the Ministry of Environment of Japan.

Open Access This article is distributed under the terms of the Creative CommonsAttribution Licensewhich permits any use, distribution, and reproduction in any medium, provided the original author(s) and the source are credited. 


\section{References}

Akashi O, Hanaoka T (2012) Technological feasibility and costs of achieving a 50\% reduction of global GHG emissions by 2050: Mid- and long-term perspectives. Sustain Sci 7:139-156. doi:10.1007/s11625-012-0166-4

Akashi O, Hanaoka T, Matsuoka Y, Kainuma M (2011) A projection for global CO2 emissions from the industrial sector through 2030 based on activity level and technology changes. Energy 36:1855-1867. doi:10.1016/j.energy.2010.08.016

Akashi O, Hijioka Y, Masui T, Hanaoka T, Kainuma M (2012) GHG emission scenarios in Asia and the world: the key technologies for significant reduction. Energy Econ. doi:10.1016/j.eneco.2012.04.011

De Beer JG, Worrell E, Blok K (1998) Future technologies for energy efficient iron and steelmaking. Annu Rev Energy Environ 23:123-205. doi:10.1146/annurev.energy.23.1.123

Dooley JJ, Dahowski RT, Davidson CL, Wise MA, Gupta N, Kim SH, Malone EL (2006) Carbon dioxide capture and geologic storage. Global energy technology strategy program

EC (2011) Special Eurobarometer 364: public awareness and acceptance of CO2 capture and storage. European Commission, Brussels

Energy and Environment Council (2012) Toward strategy formulation -what is indicated by national debate-. http:/www.npu.go.jp/policy/policy09/pdf/20120904/shiryo1-1.pdf. Accessed 15 October 2012 (in Japanese)

Hanaoka T, Akashi O, Kanamori Y, Ikegami T, Kainuma M, Hasegawa T, Fujimori S, Matsuoka Y, Hibino G, Fujiwara K, Motoki Y (2009) Global greenhouse gas technological mitigation potentials and costs in 2020 (Second Edition). AIM Interim Report. http://2050.nies.go.jp/report/aim/AIM-InterimReport_ EnduseGlobal.pdf. Accessed 15 October 2012

Hendriks C, Graus W, van Bergen F (2004) Global carbon dioxide storage potential and costs. Ecofys, Utrecht

Higashi S, Kawase R, Matsuoka Y (2012) A study on world steel demands considering service demand change. Environ Res 68(5):I_15-I_24

Hijioka Y, Matsuoka Y, Nishimoto H, Masui T, Kainuma M (2008) Global GHG emission scenarios under GHG concentration stabilization targets. J Glob Environ Eng 13:97-108

IEA (International Energy Agency) (2008) CO2 capture and storage, a key carbon abatement option. OECD/ IEA, Paris

IEA (International Energy Agency) (2009) Energy technology transitions for industry. OECD/IEA, Paris

IEA (International Energy Agency) (2010) Energy technology perspectives 2010. OECD/IEA, Paris

IPCC (Intergovernmental Panel on Climate Change) (2000) Special report on emissions scenarios. Cambridge University Press, Cambridge

IPCC (Intergovernmental Panel on Climate Change) (2005) Carbon dioxide capture and storage. Cambridge University Press, Cambridge

IPCC (Intergovernmental Panel on Climate Change) (2007) Climate change 2007: mitigation. Cambridge University Press, Cambridge

Kainuma M, Matsuoka Y, Morita T (eds) (2003) Climate policy assessment: Asia-Pacific integrated modeling. Springer, Tokyo Berlin Heidelberg New York

Krey V, Riahi K (2009) Implications of delayed participation and technology failure for the feasibility, costs, and likelihood of staying below temperature targets? Greenhouse gas mitigation scenarios for the $21 \mathrm{st}$ century. Energy Econ 31:S94-S106. doi:10.1016/j.eneco.2009.07.001

Kriegler E, Weyant J, Blanford G, Clarke L, Tavoni M, Krey V, Riahi K, Fawcett A, Richels R, Edmonds J (2013) Overview of the EMF 27 study on energy system transition pathways under alternative climate policy regimes. Clim Change, this issue

Okagawa A, Masui T, Akashi O, Hijioka Y (2012) Assessment of GHG emission reduction pathways in a society without carbon capture and nuclear technologies. Energy Econ 34:S391-S398. doi:10.1016/ j.eneco.2012.07.011

Rogelj J, Hare W, Lowe J, van Vuuren DP, Riahi K, Matthews B, Hanaoka T, Jiang K, Meinshausen M (2011) Emission pathways consistent with a 2 degrees C global temperature limit. Nat Clim Chang 1(8):413418. doi:10.1038/NCLIMATE1258

UN (United Nations) (2009) World population prospects: the 2008 revision. Population Division, Department of Economic and Social Affairs, United Nations

Worrell E, Price LK, Martin N, Hendriks C, Meida LO (2001) Carbon dioxide emissions from the global cement industry. Annu Rev Energy Environ 26:303-329. doi:10.1146/annurev.energy.26.1.303 